\title{
Development of a highly sensitive sampler for atmospheric monitoring of 8-H ambient ozone concentrations
}

\author{
Gülnihal KARA ${ }^{+}$ \\ Konya Technical University, Department of Environmental Engineering, 42075 Campus, Konya, Turkey
}

\begin{abstract}
A new passive sampler reinforced with a composite membrane was developed to determine the 8-h ozone $\left(\mathrm{O}_{3}\right)$ concentration in ambient air. The composite membrane's water absorption capacity and porosity values were found analyzing its surface morphology using Scanning Electron Microscopy (SEM).Ozone adsorption performance of this sampler was tested by a badge-type sampler and automated measurement results. The developed sampler gave results equivalent $\left(\mathrm{R}^{2}=0.85\right)$ to those of automated $\mathrm{O}_{3}$ monitors, and its experimental sampling rate was determined to be $55 \mathrm{~cm}^{3} / \mathrm{min}$, approximately two times higher than the rate of the badge-type sampler. The detection limit obtained $\left(5.3 \mu \mathrm{g} / \mathrm{m}^{3}, 8 \mathrm{~h} \mathrm{sampling}\right)$ in the study was adequate for winter-period samplings where in the ozone concentration is low in urban and semi-urban areas. Multimedia sampling results revealed that the results of the developed passive sampler had a high repeatability (RSD < 20\%). Passive samplers reinforced with composite membranes were tested by badge-type samplers performing simultaneous samplings in land conditions. Area sampling results indicated that badge-type samplers were not suitable for 8-h area samplings, but tube-type samplers could be used.
\end{abstract}

Keywords: Atmospheric monitoring, Chitosan, Ozone, Passive sampler, Polyethylene glycol

\section{Introduction}

The Air Quality Standard is specified as $120 \mu \mathrm{g} / \mathrm{m}^{3}$ (maximum 8-h mean value) in the European Directives for ozone to protect human health [1]. Automated analyzers or active sampling methods allowing continuous measurements and featuring an expensive ultraviolet (UV) photometry technique are used for the tropospheric ozone measurements. The measurement of ozone, which is in high concentration levels in rural areas, is difficult by these techniques. In recent years, alternative strategies have been developed to active sampling and automated analyzers [2, 3]. The use of passive samplers in high pollutant concentration areas is an alternative strategy to automated analyzers. Recently, the rate of using passive samplers has increased in studies evaluating the spatial distribution of tropospheric ozone and other pollutants [4-7]. A typical passive sampler consists of a collecting medium with a high affinity for the related pollutant and a static region between the atmosphere and the collecting medium where diffusion takes place. Gas molecules diffuse between the static regions after passing a barrier, and then are collected on samplers by sorption onto the collecting medium [8]. Passive samplers are prepared by different configurations (tube

This is an Open Access article distributed under the terms of the Creative Commons Attribution Non-Commercial License (http://creativecommons.org/licenses/by-nc/3.0/) which permits unrestricted non-commercial use, distribution, and reproduction in any medium, provided the original work is properly cited.

Copyright (C) 2020 Korean Society of Environmental Engineers
[7, 9] and badge [10-13]) and techniques. Various sorption reagents such as DPE (1, 2-di (4-pyridyl)-ethylene) [14-16], nitrite [17, 18], indigo [19], indigo/carmine compounds [20, 21] are used on the collecting medium. However, because reagents, except for DPE and nitrite, do not specifically react with $\mathrm{O}_{3}$, they can react with other air pollutants in the atmosphere such as mono-nitrogen oxides (NOx) and polyacrylonitrile (PAN), resulting in positive errors [18, 22]. Two factors that affect the sampling rate of passive samplers are the face velocity and photolysis, which are related to sun light. The temperature effect on the sampling rate is less in membrane-transitive passive samplers. It was determined that the use of polyethylene (PE) membrane in passive samplers increased gas permeability and the performance of the sampler by acting as a diffusion barrier [23-25]. However, despite all those technological advances, suggested sampling time is two weeks in commercial passive samplers, and it can be said that a comparison of the values obtained from these samplers with the 8-h maximum limit value is not a realistic case. This study aims to decrease the sampling time and increase the overall performance. For these purposes, a new tube-type passive sampler was developed by employing a DPE coated silica gel as a collection medium and a porous and

\author{
$\dagger$ Corresponding author \\ Email: gkara@selcuk.edu.tr \\ Tel: ++90 3322238678 Fax: +90 3322412300 \\ Orchid: 0000-0002-1955-1596
}

Received October 10, 2019 Accepted December 26, 2019 
biodegradable membrane made of chitosan (CS)/polyethylene glycol (PEG) composite cross-linked by a natural sugar as a turbulence limiting diffuser. CS, featured as a diffusion barrier in the sampler, is a biodegradable, non-toxic, non-mutagen, and high porous polymer used in numerous sectors such as, paper production, textile paint, heavy metal chelation, wastewater treatment, cosmetics, biomedical applications, and drug production. PEG, on the other hand, was used to enhance the chemical resistance of the CS [26, 27]. Non-toxic or non-mutagen invert brown sugar, a biological cross-linker, was used for the preparation of the CS/PEG membrane in this study instead of a chemical cross-linker to preserve the water balance of the membrane and to increase its flexibility and tensile strength. The sampling rate of the classical passive sampler was increased by the membrane, imparting an 8-h ozone sampling period feature. In the station performing continuous ozone measurements by automated $\mathrm{O}_{3}$ monitors, the sampling rates of the samplers were compared by performing simultaneous samplings using a badge-type passive sampler, developed in Eskişehir University at the department of Environmental Engineering, and a tube-type sampler, reinforced with a composite membrane. The repeatability of the developed sampler was determined by multimedia samplings. Moreover, real environment trials and the validation of the developed passive sampler were conducted in the ambient air of Konya and Ankara in Turkey. The properties of both the developed passive sampler and commercial passive samplers used in ozone measurement were presented in Table 1, which also shows that the developed passive sampler has the highest sampling rate among commercial passive samplers and its detection limit is lower than the Gradko sampler and higher than the Passam and Radiello sampler [28-30].

In this study, the composite membrane has absorbed the humidity in the air and increased the molecular diffusion rates of the non-humid ozone molecules. In addition, the small pore sized structure of the developed membrane allowed the fast passage of non-humid ozone molecules and leads to the delayed breakthrough of the collecting media. Chitosan used in the composite membrane is environmentally friendly biodegradable, non-toxic, non-mutagen, and high porous polymer. The resistance to environmental factors (such as resistance to tearing and rupture) was increased using a crosslinking agent and, importantly, it is biodegradable. Another purpose of using the cross-linking agent was to retain the amine groups by forming a branched structure on the membrane, thereby increasing the hydrophilicity of the membrane. Moreover, this fea- ture was incorporated to the membrane not using toxic or mutagenic chemicals but using brown sugar, a biological cross-linker. In ozone sampling, the detection of approximately $30 \%$ lower $\mathrm{O}_{3}$ concentrations based on $\mathrm{NO}_{2}$ formation as a result of photochemical reactions between ozone and NO is an important problem. The membrane with a $28 \%$ water absorption capacity increased the theoretical sampling rate by about 9 times by absorbing moisture from the air and preventing the collecting medium from exposure to direct sunlight. In passive samplers, Eddy diffusion, which causes air turbulence at the sampler inlet, shortens the diffusion path length. This study has shown that the composite membrane not only has high gas permeability but also is a good turbulence barrier. In addition, in the ozone analysis with this passive sampler, non-complex UV spectrophotometric method is used that can be specifically and generally applied in all laboratories. Low detection limits (5.3 $\mu \mathrm{g} / \mathrm{m}^{3}$, $8 \mathrm{~h}$ sampling) allow this sampler to be used in urban, semi-rural and rural area sampling.

\section{Material and Methods}

\subsection{Preparation of the Samplers}

The upper part of the body of the classical tube-type sampler prepared in laboratory conditions as shown in Fig. 1(a) was coated by a $0.5 \mathrm{~cm}$ fiberglass, $4 \mathrm{~cm}$ silica gel (pore diameter: $0.063-0.200$ $\mathrm{mm}$; Merck) and $0.5 \mathrm{~cm}$ fiberglass, successively. A stainless steel wire and SKC Teflon filter $(4 \mu \mathrm{m})$ were used for a diffusion barrier, and $5 \%$ deactivated silica was used for an adsorbent. Before coating, the deactivated silica was washed with water and methanol and dried by nitrogen gas at a $0.4 \mathrm{~L} / \mathrm{min}$ flow rate. The inactive substance was then coated with $1.5 \mathrm{~mL} \mathrm{DPE}$ aqueous solution (1,2-bis (4-pyridyl)ethylene, Aldrich) [31]. The solution was prepared by adding $45.5 \mathrm{~mL}$ acetic acid $+4.5 \mathrm{~mL}$ ultra distilled water (Milli-Q) into $0.075 \mathrm{~g}$ of DPE (Aldrich) weighed in precision balance. After coating, the second drying step was carried out with nitrogen gas of $0.4 \mathrm{~L} / \mathrm{min}$ for $15 \mathrm{~min}$. The composite membrane was synthesized using $1.34 \mathrm{~g}$ of CS (Fluka, deacetylation, 85\%), $0.66 \mathrm{~g}$ of PGE (Fluka, molecular weight, 20000$)$ with a proportion of $70 / 30(\mathrm{w} / \mathrm{w})$ and $9 \mathrm{~g}$ of natural sugar in $100 \mathrm{~mL}$ of $2 \%$ solution of acetic acid. Researchers have used various chemicals such as glutaraldehyde [32] and cellulose acetate [33] for cross-linking reactives. Glucose

Table 1. The Properties of Both the Developed Passive Sampler and Commercial Passive Samplers Used in Ozone Measurement

\begin{tabular}{|c|c|c|c|c|c|c|}
\hline Sampler Type & Inlet & $\begin{array}{l}\text { Trapping } \\
\text { Reagent }\end{array}$ & $\begin{array}{l}\text { Sampling Rate } \\
\left.(\mathrm{mL} \mathrm{min})^{-1}\right)\end{array}$ & $\begin{array}{l}\text { Limit of Detection } \\
\text { (LOD) }\end{array}$ & $\begin{array}{l}\text { Sampling } \\
\text { Time }\end{array}$ & Analysis \\
\hline $\begin{array}{l}\text { Gradko } \\
\text { (Palmes tube) }\end{array}$ & - & $\mathrm{NaNO}_{2}$ & 15.5 & $\begin{array}{c}10 \\
\text { (for } 4 \text { weeks exposures) }\end{array}$ & 2-4 weeks & Ion Chromatography \\
\hline Ogawa & - & $\mathrm{NaNO}_{2}$ & 21.8 & - & $2-3$ weeks & Ion Chromatography \\
\hline Radiello & $\begin{array}{c}\text { PE } \\
\text { membrane }\end{array}$ & DPE & 24.6 & $\begin{array}{c}2 \\
\text { (for } 7 \mathrm{~d} \text { Exposures) }\end{array}$ & $3-7 \mathrm{~d}$ & Spectrophotometry \\
\hline Passam & - & $\mathrm{NaNO}_{2}$ & 11.2 & (for $14 \mathrm{~d}^{2}$ exposure) & 1-4 weeks & Ion Chromatography \\
\hline The developed sampler & $\begin{array}{l}\text { Composite } \\
\text { membrane }\end{array}$ & DPE & 55 & $\begin{array}{c}5.3 \\
\text { (for } 8 \mathrm{~h} \text { ) }\end{array}$ & 8 h-15d & Spectrophotometry \\
\hline
\end{tabular}



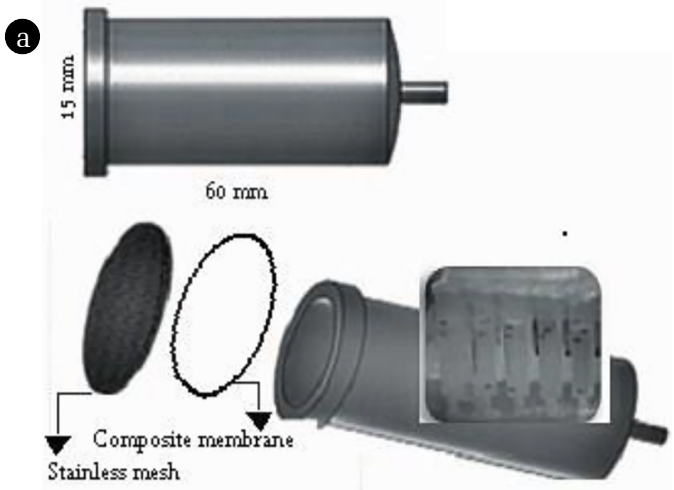

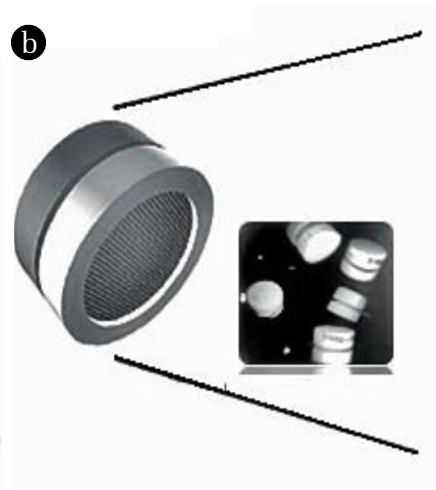

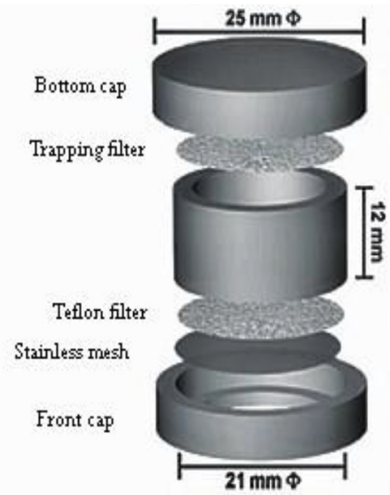

Fig. 1. Laboratory-built passive samplers (a) Tube-type, (b) Badge-type.

shows similar cross-linking properties to glutaraldehyde [34]. In this study, brown sugar (9\%), a non-toxic biological cross-linker, was used as a cross-linking reactive.

After adjusting the $\mathrm{pH}$ value to 3-4 by HCI, Tawny-brown fluid solution was transferred to $75 \mathrm{~mm}$-thick glass petri dishes in a thickness of approximately 7-8 $\mathrm{mm}$ and then allowed to incubate in an oven at $55^{\circ} \mathrm{C}$ for $8 \mathrm{~h}$. After the incubation process, a circular cross-section with a $16 \mathrm{~mm}$ diameter was taken to determine the porosity of the membrane before the extraction treatment by hot water. The weight and volume of the membrane cross-section were measured. Afterwards, the membrane was applied to eversion in a $2 \% \mathrm{NaOH}$ solution at room temperature (RT), and extracted in a water bath at $80^{\circ} \mathrm{C}$ for $8 \mathrm{~h}$. Then it was dried at RT for $8 \mathrm{~h}$. After the extraction process, its weight and volume were measured again. The surface morphology of the membrane was observed by $50 \mathrm{VP}$ Zeiss Supra SEM equipment.

The porosity of the composite membrane was calculated using the following equation.

$$
\text { Porosity }(\%)=\left(1-\frac{\delta_{1}}{\delta_{2}}\right) x 100
$$

where $d_{1}$ shows the density of the membrane cross-section after extraction, and $\mathrm{d}_{2}$ shows the density of the membrane cross-section before extraction. It was assumed that all the pores in the membrane were completely filled with water.

The components and dimensions of the badge-type passive sampler used in the study, as shown in Fig. 1(b), are as follows: a polyethylene body, a barrier made from stainless steel wire and SKC Teflon (PTFE) filter ( $4 \mu \mathrm{m})$, a $20 \mathrm{~mm}$ inner diameter, a 25 $\mathrm{mm}$ outer diameter, a $20 \mathrm{~mm}$ diffusion path length, an adhesion environment containing a Whatman 40 cellulose filter $(8 \mu \mathrm{m}) / \mathrm{GFA}$ $(1.6 \mu \mathrm{m})$ filter and $200 \mu \mathrm{L}$ an adsorbent with a composition of $74 \%$ glycerol (Merck), $15 \% \mathrm{Na}_{2} \mathrm{CO}_{3}$ (Merck), and 11\% $\mathrm{NaNO}_{2}$ (Merck). Fig. 1(b) shows the schematic views and images of the passive samplers prepared in the laboratory.

\subsubsection{Water absorption capacity measurement}

A composite membrane can have a branched structure due to containing various types of hydrogen bonds and groups bound to the hydrogen bonds. The cross-linking agent consumes amine groups in the branched structure and increases the hydrophilic degree of the membrane by breaking intermolecular and intramolecular hydrogen bonds [35]. The hydrophilic or hydrophobic degree of the composite membrane was evaluated by determining water absorption percentage, which is also related to the porosity of the membrane. First, the dry mass of the cross-section of $5 \times 5 \mathrm{~cm}$ membrane was weighed, and then the cross-section of the membrane was kept in ultra-pure water at RT for $24 \mathrm{~h}$. Finally, its mass was weighed again after the excess water was removed by a blotting paper. Water absorption percentage was calculated using these two values through the following equation below [36].

$$
\text { Water absorption }(\%)=\frac{\mathrm{W}_{2}-\mathrm{W}_{1}}{W_{2}} \times 100
$$

Where, $\mathrm{W}_{1}$ shows the weight of dry membrane and $\mathrm{W}_{2}$ shows the weight of membrane soaked in water for $24 \mathrm{~h}$, at RT.

\subsubsection{Determination of sampling rate}

The ozone concentration in the air was calculated using Fick's First Law for badge- and tube-type samplers.

$$
\mathrm{C}_{\text {ozone }}=\left(\frac{\mathrm{m}_{\mathrm{a}}-\mathrm{m}_{\mathrm{b}}}{u_{i} \cdot t}\right)
$$

where $m_{a}$ shows the mass of the ozone ( $\left.\mu \mathrm{g}\right)$ found on the sorbent, $m_{b}$ shows the mass of the ozone $(\mu \mathrm{g})$ on a non-exposed sorbent (a blank), $\mathrm{t}$ (min) shows the sampling time, $\mathrm{C}$ shows the ambient concentration $\left(\mu \mathrm{g} / \mathrm{m}^{3}\right)$ of the ozone, and $U_{i}$ shows the uptake rate of the ozone $\left(\mathrm{m}^{3} / \mathrm{min}\right)$. A " $\mathrm{v}$ " value (conversion factor from ozone to PA) of 0.448 in the Fick's First Law was used for the tube-type sampler.

Uptake rate is calculated through the diffusion coefficient and the geometry of the tube as follows:

$$
\mathrm{U}_{\mathrm{i}}=D_{i} x\left(\frac{A}{L}\right)
$$

where Di shows the diffusion coefficient of the ozone in air $\left(\mathrm{cm}^{2} / \mathrm{min}\right)$, A shows the area of the sampler $\left(\mathrm{cm}^{2}\right)$, and $\mathrm{L}$ shows the length of the diffusion zone $(\mathrm{cm})$. 


\subsection{Sampler Analysis}

The ozone collected in the adhesion environment for badge-type samplers was analyzed as $\mathrm{NO}_{3}^{-}$a wavelength of $410 \mathrm{~nm}$ by a spectrophotometer, based on the EPA 352.1 method, after extracting it with18 MW distilled water. Nitrate ion concentration was determined based on the reference calibration graph obtained using standard sodium nitrate (Merck) at a range from 1 to $10 \mu \mathrm{g} / \mathrm{mL}$.

After sampling the tube-type samplers, the silica gel inside the tubes was extracted with $4.5 \mathrm{~mL}$ of $0.023 \mathrm{M} \mathrm{MBTH}$ (3-methyl-2-benzothiazolinone hydrazine, Fluka) solution, and the absorbance of the extracted solution was measured by a spectrophotometer at a wavelength of $430 \mathrm{~nm}$ [7]. The ozone concentration was determined based on the reference calibration graph obtained using standard ozone gas at a range from 2.67 to $14.22 \mu \mathrm{g} / \mathrm{mL}$. PA (pyridine-4-aldehyde) concentration of the hydrolysis product was measured by a spectrophotometer at a wavelength of $430 \mathrm{~nm}$.

\section{Results and Discussion}

\subsection{Membrane Characterization}

In this study, a gel-like membrane was produced first, and then a porous structure, shown in Fig. 2(a), was formed after extracting the membrane by hot water. The surface morphology of the membrane was obtained by SEM, as shown in Fig. 2(b).

Fig. 2(b) shows that there were very small pores on the surface of the composite membrane. This phenomenon may have occurred because brown sugar was used as a cross-linking agent to increase the flexibility and tensile strength of the membrane. The amount of cross-linking agent in the membrane significantly affects the porous structure. In a study conducted by [26], when the amount of cross-linking agent was $0.3 \%$, the porosity was $62 \%$, and when the concentration was increased to $2 \%$, the porosity decreased to $25 \%$. In the present study, the masses of the composite membrane before and after extraction were 1.254 and 0.445 g, respectively; the thickness of the membrane was $1 \mathrm{~mm}$, and the porosity calculated using the Eq. (1) was $65 \%$. The dry mass of the membrane was $0.442 \mathrm{~g}$, while its mass was $0.621 \mathrm{~g}$ after keeping it in ultra-pure water for $24 \mathrm{~h}$. Water absorption of the composite membrane calculated using the Eq. (2) was $28 \%$. Water absorption percentage is important for designing air samplers. A higher level of pollutant gas can be adsorbed and shorter sampling times can be achieved through the absorption of moisture from the air by the composite membrane.

Water vapor is absorbed by polar sorbents; their breakthrough capacity for the analyte is thereby reduced for most compounds. Collecting media may also be affected by humidity. Moisture may affect a media's collection efficiency. Gas molecules with low mass move faster than those with large mass. The mass of humid air is higher than that of the same volume of non-humid air. Consequently, the speed of the gas molecules increases with humidity absorbed in the diffusion barrier thus the gas is diffused faster from the static area to the collecting media. In such a case, a greater quantity of analyte is collected during a shorter sampling period [37, 38].

More pollutant gas adsorptions by adsorbent and shorter sampling times can be achieved through the absorption of moisture from the air by the composite membrane. Moreover, this feature was incorporated to the membrane not using toxic or mutagenic chemicals but using brown sugar, a biological cross-linker.

\subsection{Validation of Passive Sampler}

In 8-h and 15-d sampling periods, the standard deviation of 20 blank samples placed in the semi-urban and urban area was calculated and the detection limit was determined as three times the standard deviation. The 15-d average blank value was found to be $0.58 \pm 0.15 \mu \mathrm{g}$ by placing 20 closed badge-type samplers at five different points protecting them from sun light. The 8-h average blank value was found to be $0.14 \pm 0.22 \mu \mathrm{g}$ by placing 20 closed (at the head) tube-type samplers at five different points protecting them from sun light.

The repeatability of the badge and tube type samplers used in the study was determined by the relative standard deviation (RSD) of the blank results in the first step, and the area sampling results in the following step, which was calculated according to the following equation:
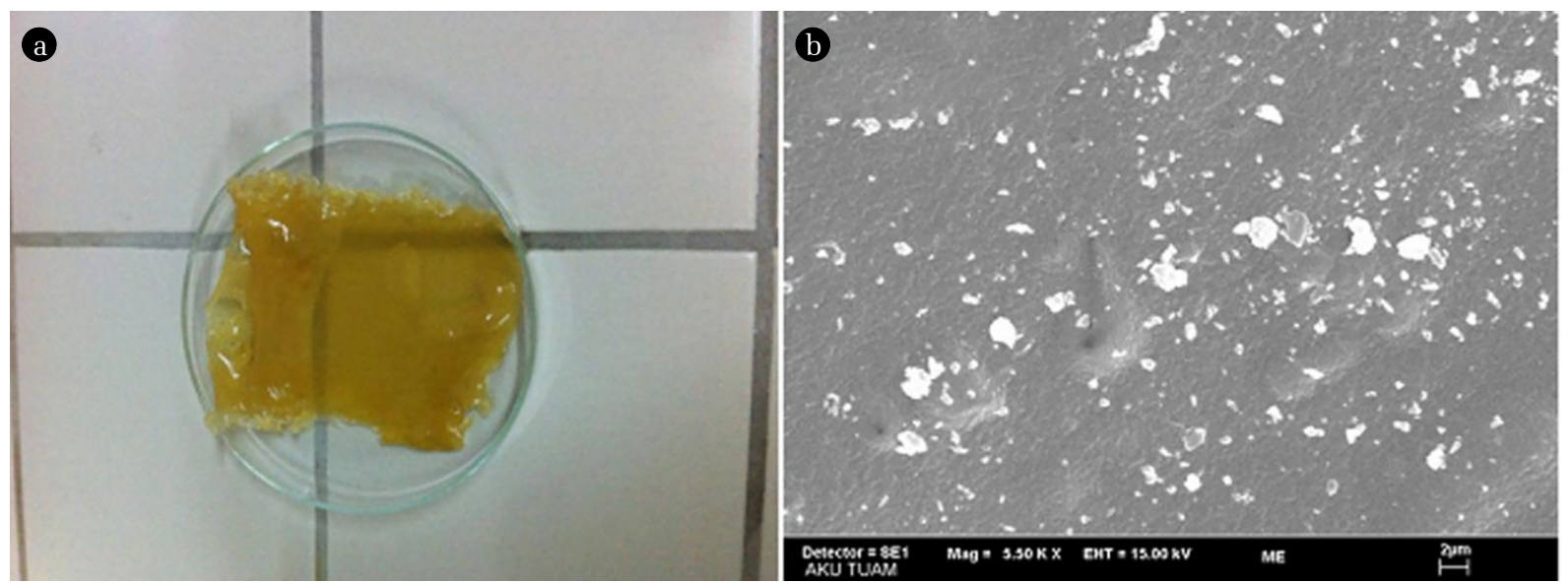

Fig. 2. (a) Laboratory image of composite membrane, (b) SEM micrograph of composite membrane. 


$$
R S D(\%)=\frac{S x 100}{\bar{X}}
$$

Where, s shows the standard deviation of sampling results of the same point and shows arithmetic mean of sampler results.

RSD $<10$ was determined for 20 tube type blank samplers in the 8-h sampling period while RSD $<20$ was determined for both tube and badge type blank samplers in the 15-day sampling period. RSD values were determined to be between 15\% and $25 \%$ in eight different regions where five samplers were placed in each region.

The theoretical sampling rate of the classic tube-type sampler was calculated to be $4.691 \mathrm{~cm}^{3} / \mathrm{min}$, setting $A$ at $1.767 \mathrm{~cm}^{2}$ and $\mathrm{L}$ at $6 \mathrm{~cm}$ constant, while that of the badge-type sampler was calculated to be $17.502 \mathrm{~cm}^{3} / \mathrm{min}$, setting A at $3.461 \mathrm{~cm}^{2}$, L at $2.1 \mathrm{~cm}$, and molecular diffusion rate coefficient at $0.177 \mathrm{~cm}^{2} / \mathrm{s}$ (at $25^{\circ} \mathrm{C}$ and $1 \mathrm{~atm})$. To determine the experimental sampling rate, 2 sets of samplings with 10 samplers, were conducted in a region where online ozone measurement was performed in a period having an average temperature of $14^{\circ} \mathrm{C}$, a relative humidity of $35 \%$, and a wind velocity of $>1 \mathrm{~m} / \mathrm{s}$. Online ozone measurement results were taken for reference, and $U_{i}$ (experimental sampling rate) calculated using $\mathrm{C}_{\text {ozone }}$, the amount of ozone collected in the collecting media (ma) and the amount of ozone collected in the blank (mb); the values in equation (3) are shown in Table 2 below.

Average experimental sampling rates were found to be 55 $\mathrm{cm}^{3} / \mathrm{min}$ and $22.47 \mathrm{~cm}^{3} / \mathrm{min}$ for the tube-type and badge-type samplers, respectively. As shown in the table1, the developed passive sampler had a higher sampling rate than the current samplers and yielded equivalent results to those of automatic analyzer (Fig. 3).

A Gradko sampler is a Palmes type sampler which does not use a membrane as the diffusion barrier. Aerosol particles that contain high levels of nitrate lead to interference. Gradko tube type sampler is considered to have irreversible uptake of ozone on collecting medium. However, in this study, ozone diffused into the DPE by passing through the porous membrane by means of a different method. This method enabled the prevention possible attempts by blocking the entry of aerosols into the sampler that could react with DPE or ozone. Moreover, it was considered that the porous membrane prevented the escape of the ozone retained in the collecting medium to outdoor air, and thus, more ozone was retained in the collecting medium. In the Radiello sampler, PE membrane is used as the diffusion barrier. The developed membrane is hydrophilic, whereas the PE membrane is hydrophobic.

The relationship between the results of a passive sampler reinforced with composite membrane and automated $\mathrm{O}_{3}$ monitors results was investigated at a station belonging to the Air Quality
Monitoring Network in Ankara, Turkey. The sampling rates of developed passive samplers were determined by correlating the amounts of ozone collected in the passive sampler (between March 21 and April 4, 2016) with the UV-photometric analyzer concentration values in Ankara/Turkey. The concentration values, obtained using the automatic analyzer were provided by the National Air Quality Monitoring Network coordinated by Turkish Ministry of Environment and Urbanization. Automatic analyzers are regularly calibrated every three months with portable $\mathrm{O}_{3}$ generators certified with NIST UV long path photometer standards. Passive samplers were located in the shelter at a minimum distance of $3 \mathrm{~cm}$ between them and as close to the height of the sampling nozzle of automatic analyzers as possible. Passive samplers ( 5 blanks and 5 samplers) were subjected to the ambient air at the sampling point for $8 \mathrm{~h}$ (09.00-17.00) on and 13 successive days. Fig. 3 shows actual environment sampling results; these are in agreement with the results obtained by the UV-photometric measurement method, which was accepted as the reference method.

When the correlation of the results obtained for two different samplings was evaluated by regression analysis, the concordance $\left(R^{2}=0.855\right)$ between two methods was good enough, as shown in Fig. 3. Researchers have generally preferred to use active samplers or automatic analyzers to evaluate passive samplers. In these studies, the relationship between active and passive sampling results was

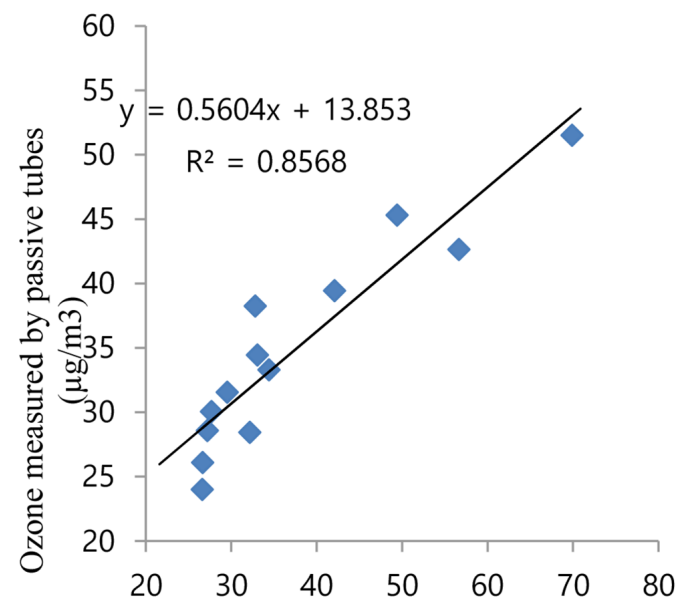

Ozone measured by automated ozone monitors $(\mu \mathrm{g} / \mathrm{m} 3)$

Fig. 3. The relationship between atmospheric concentrations of ozone measured by ozone monitors and by passive tubes using membrane as turbulence limiting diffuser (Ankara-Turkey).

Table 2. Experimental Sampling Rates Calculated For the Passive Sampler

\begin{tabular}{cccc}
\hline $\begin{array}{c}\text { Ozone measured by automated } \\
\text { ozone monitors }\left(\boldsymbol{\mu g} / \mathbf{m}^{\mathbf{3}}\right)\end{array}$ & $\begin{array}{c}\text { Average Blank Value }(\boldsymbol{\mu g}) \\
(\mathbf{n}=\mathbf{5})\end{array}$ & $\begin{array}{c}\text { Ozone measured by Passive Sampling }(\boldsymbol{\mu g}) \\
(\mathbf{n}=\mathbf{5})\end{array}$ & $\begin{array}{c}\text { Average Experimental } \\
\text { Sampling Rate }\left(\mathbf{m}^{\mathbf{3}} / \mathbf{h}\right)\end{array}$ \\
\hline & & The tube-type samplers & \\
\hline $27.68(8 \mathrm{~h})$ & $0.29 \pm 0.06$ & $1.08 \pm 0.12$ & $0.592 \mathrm{E}-04 \pm 0.102 \mathrm{E}-04$ \\
$29.52(8 \mathrm{~h})$ & $0.34 \pm 0.15$ & $1.08 \pm 0.30$ & $0.527 \mathrm{E}-04 \pm 0.107 \mathrm{E}-04$ \\
\hline & $0.38 \pm 0.12$ & The badge-type samplers \\
\hline & & $0.78 \pm 0.11$ & $0.224 \mathrm{E}-04 \pm 0.126 \mathrm{E}-04$ \\
\hline
\end{tabular}


determined in the range of $\left(\mathrm{R}^{2}=0.67-0.88\right)$ because environmental conditions such as temperature, wind velocity and pressure had a stronger effect on passive sampling performed in outdoor air [9, 39, 40]. At levels below $30 \mu \mathrm{g} / \mathrm{m}^{3}$, the measurements obtained with an automated ozone monitor were similar to those obtained with a passive sampler; however, it was also seen in this study that automated ozone monitor exhibited higher results at higher concentrations. As the automated ozone monitor method was accepted as the reference method, there is no doubt that its results are accurate. This method yields results in short periods such as an $\mathrm{h}$; this is not sufficient time for substances that will cause positive or negative interference in the air and consume ozone. However, 8-h passive sampling, which is 8 times longer that for active sampling is adequate for reactive species such as ozone to react and be consumed. Therefore, maintaining a high correlation between passive and active sampling of reactive species, including formaldehyde and ozone, is very difficult in ambient air. The relationship between passive and active sampling was higher in this study than in other studies. According to the $\mathrm{F}$ test results, there was no difference at a 99\% significance level between the results of automatic analyzer and passive sampling $(\mathrm{p}<0.01)$.

The \% accuracy values of the developed passive samplers were calculated according to the following equation.

$$
\text { Accuracy }(\%)=\frac{\mathrm{X}_{\mathrm{ref}}-\mathrm{X}}{\mathrm{X}_{\mathrm{ref}}} \times 100(6)
$$

Where $\mathrm{X}_{\text {ref }}$ shows atmospheric concentration of ozone measured by reference method and Xshows atmospheric concentration of ozone measured by passive tubes using membrane as turbulence limiting diffuser.

UV-photometric analyzer results were used as reference method values in determining the accuracy values. The mean accuracy of tube type passive samplers was determined as $6.82 \%$.

The storage stability of the developed passive sampler was investigated in two stages as pre-sampling (shelf life) and post-sampling (storage). Five ready-to-use tube type passive samplers were stored in the refrigerator at $+4^{\circ} \mathrm{C}$ for 3 months and these newly prepared samplers and the old samples were left to $8 \mathrm{~h}$ sampling in semi-rural area. The results were compared and the difference between the old and new samplers was found to be quite small (RSD < 10) and appropriate according to CEN protocol. The storage stability of the passive samplers was determined by exposing five passive samplers to an ozone concentration of $52.01 \mu \mathrm{g} / \mathrm{m}^{3}$ and then leaving them in a refrigerator at $4^{\circ} \mathrm{C}$ for three months. The analyses showed that the passive samplers developed and produced in the present study remained robust for three months, from sampling to analysis, under laboratory conditions at $4^{\circ} \mathrm{C}$.

$\mathrm{O}_{3}$ recoveries was performed by spiking the standard ozone gas in the sampler and the lowest recovery was $85 \%$ for $2.67 \mu \mathrm{g} / \mathrm{mL}$ ozone concentration

\subsubsection{Evaluation of passive samplers under field conditions}

Passive samplers reinforced with a composite membrane were tested in land conditions at the Selçuk University Campus in Konya, which is accepted to be a semi-urban area. The passive samplers were subjected to ambient air to test their ozone absorption performance. Samplers were placed in dark-colored plastic shelters at $100 \mathrm{~cm}$ above the earth to protect them from environmental conditions such as rain and sun light. Badge and tube-type samplers were placed in the same shelters and subjected to two different sampling times: $8 \mathrm{~h}$ and $15 \mathrm{~d}$. The results are shown in Table 3.

Table 3 indicates that although the sampling rates of badge-type samplers were higher than those of tube-type samplers [41], parallel sampling results showed that higher concentration values were obtained with tube-type samplers reinforced with the composite membrane. The experimental sampling rate was found to be higher in the tube-type sampler reinforced with the composite membrane than in the badge-type sampler. This result was also supported by the sampling results. Area sampling results revealed that the current badge-type sampler was not suitable for 8-h area samplings, but that tube-type samplers could be used for that purpose. Because

Table 3. Comparison of Atmospheric $\mathrm{O}_{3}$ Concentrations from Different Samplers

\begin{tabular}{lccccc}
\hline \multirow{2}{*}{ Exposure time } & \multicolumn{2}{c}{ Badge-type sampler } & \multicolumn{2}{c}{ Tube-type sampler } \\
\cline { 2 - 3 } \cline { 5 - 6 } & Summer Period & Winter Period & & Summer Period & Winter Period \\
\hline 8-h-sampling (09.00-17.00) & Not determined & Not determined & & $81.53 \pm 0.29$ & $21.46 \pm 0.28$ \\
15 d & $38.45 \pm 0.49$ & $10.78 \pm 0.33$ & & $52.01 \pm 0.52$ & $16.52 \pm 0.32$ \\
\hline
\end{tabular}

Table 4. Concentrations of $\mathrm{O}_{3}$ in Konya's Atmosphere as Determined by Tube-type Passive Sampling $\left(\mu \mathrm{g} / \mathrm{m}^{3}\right)$

\begin{tabular}{lccc}
\hline Site type/location & Mean Conc. \pm S.D. $(\mathbf{n}=\mathbf{5})$ & Min & Max. \\
\hline Urban/Selçuklu & $79.05 \pm 0.27$ & 78.16 & 80.55 \\
Sub-Urban/Selçuklu & $88.40 \pm 0.33$ & 88.15 & 91.19 \\
Industrial-1/Selçuklu & $92.49 \pm 0.30$ & 87.99 & 93.58 \\
Industrial-2/Selçuklu & $81.77 \pm 0.26$ & 81.22 & 82.28 \\
Sub-Urban/Selçuklu & $82.75 \pm 0.28$ & 82.05 & 83.81 \\
Urban/Selçuklu & $81.57 \pm 0.21$ & 81.48 & 81.67 \\
Urban/Karatay & $69.48 \pm 0.29$ & 66.44 & 69.80 \\
Urban/Meram & $87.48 \pm 0.29$ & 86.59 & 88.56 \\
\hline
\end{tabular}


the $\mathrm{O}_{3}$ parameter could not be continuously measured by the online measurement method in the ambient air of Konya, 8-h ozone measurements (09.00-17.00) were performed by the passive sampler reinforced with the composite membrane at different locations in May. The results are shown in Table 4.

When $\mathrm{O}_{3}$ monitoring results obtained from different regions of Konya were evaluated, the highest values were observed at the sampling point (Industrial-1/Selcuklu) near the organized industrial zone in Selçuklu County, while the lowest $\mathrm{O}_{3}$ levels were found at the sampling point of Urban/Karatay, as indicated in Table 4. Similar results were obtained at the other sampling points. In a study using Gradko passive diffusion tubes to determine $\mathrm{O}_{3}$ levels in Konya in 2010, 15-day mean concentrations in the summer period were found to range from 54 to $98 \mu \mathrm{g} / \mathrm{m}^{3}$ [42]. In a study conducted by [43] using passive samplers at 60 points in İskenderun, Turkey, $\mathrm{O}_{3}$ levels were determined to range from 11 to $395 \mu \mathrm{g} / \mathrm{m}^{3}$. A study conducted by [44] using passive samplers at 49 points in Aliağa/İzmir, Turkey found that $\mathrm{O}_{3}$ concentrations ranged from 24 to $134 \mu \mathrm{g} / \mathrm{m}^{3}$. The results found in the present study were similar to the high ozone concentration levels determined in industrial and rural areas in the above-mentioned studies.

\section{Conclusions}

In this study, promising results were obtained for sampling ozone with a composite membrane reinforced passive sampler in ambient air. A composite membrane was used as a diffuser in the developed passive sampler, and higher sampling rates were obtained than the classical passive samplers. The results for 8-h sampling time were equivalent to those obtained by automated ozone monitoring. The composite membrane did not change the sampling rate even in different wind velocities by preventing the eddy diffusion resulting from the diffuser's air turbulence, which considered being the most important factor in obtaining equivalent results from online measurements with passive samplers. The developed passive sampler can be used even in winter-area samplings that include low ozone concentrations. Moreover, it is easy and practical to use and therefore does not require any specialty on its use. This study demonstrated that the developed passive sampler can be used to determine the $\mathrm{O}_{3}$ emissions at high concentration levels in summer period. The passive samplers with high repeatability (RSD < 10) and low blank values are suitable for use indoors as well as for field sampling.

\section{Acknowledgment}

This work was financed by the funds for university statutory activity.

\section{Author Contributions}

G.K. (Asst. Prof. Dr.) designed and conducted all the experiments and wrote the manuscript.

\section{References}

1. EU (European Union), Directive 2002/3/EC relating to ozone in ambient air. Journal European Communities 2002, 67, 14.

2. European Standard, EN 14625, Ambient Air Quality e Standard Method for the Measurement of the Concentration of Ozone by Ultraviolet Photometry. Brussels, Belgium 2005.

3. Chang LT, Suh HH, Wolfson JM, et al. Laboratory and field evaluation of measurement methods for one-hour exposures to $\mathrm{O}_{3}, \mathrm{PM}_{2.5}$, and CO. J. Air Waste Manage. 2001;51:1414-1420.

4. Krupa S, Legge A. Passive sampling of ambient, gaseous air pollutants: an assessment from an ecological perspective. Environ. Pollut. 2000;107:31-45.

5. Ankersmit H, Tennant N, Watts SF. Hydrogen sulfide and carbonyl sulfide in the museum environment, part 1. Atmos. Environ. 2005;39:695-707.

6. Sanz MJ, Calatayud V, Sanchez-Pen G. Measures of ozone concentrations using passive sampling in forests of South Western Europe. Environ. Pollut. 2007;145:620-628.

7. Plaisance H, Gerboles M, Piechocki A, Detimmerman F, de Saeger E. Radial diffusive sampler for the determination of 8-h ambient ozone concentrations. Environ. Pollut. 2007;148:1-9.

8. Lyman SN, Gustin MS, Prestbo EM. A passive sampler for ambient gaseous oxidized mercury concentrations. Atmos. Environ. 2010;44:246-252.

9. Sekine Y, Watts SF, Rendell A, Butsugan M. Development of highly sensitive passive sampler for nitrogen dioxide using porous polyethylene membrane filter as turbulence limiting diffuser. Atmos. Environ. 2008;42:4079-4088.

10. Tate P. Ammonia sampling using Ogawas passive samplers [dissertation]. South Florida: University of South Florida; 2002.

11. Thoni L, Seitler E, Blatter A, Neftel A. A passive sampling method to determine ammonia in ambient air. J. Environ. Monitor. 2003;5:96-99.

12. Özden Ö, Döğeroğlu T, Kara S. Assessment of ambient air quality in Eskişehir, Turkey. Environ. Int. 2008;34:678-687.

13. Özden Ö, Döğeroğlu T. Performance evaluation of a tailor-made passive sampler for monitoring of tropospheric ozone. Environ. Sci. Pollut. Res. 2012;9:3200-3209.

14. Monn C, Hangartner M. Passive sampling for ozone. J. Air Waste Manag. 1990;40:357-358.

15. Campbell GW, Stedman JR, Stevenson KJ. A survey of nitrogen dioxide concentrations in the United Kingdom using diffusion tubes, July-December 1991. Atmos. Environ. 1994;28:468-477.

16. Bernard NL, Gerber MJ, Astre CM, Saintot MJ. Ozone measurement with passive samplers: Validation and use for ozone pollution assessment in Montpellier, France. Environ. Sci. Technol. 1999;33:217-222.

17. Koutrakis P, Wolfson JM, Bunyaviroch A, Froelich S. A passive ozone sampler based on a reaction with nitrate. Res. Rep. Health Eff. Inst. 1994;63:19-47.

18. Helaleh MIH, Ngudiwaluyo S, Korenaga T, Tanaka K. Development of passive sampler technique for ozone monitoring, Estimation of indoor and outdoor ozone concentration. Talanta 2002:58:649-659.

19. Buffoni A. Ozone and nitrogen dioxide measurements in the framework of national integrated programme for the control 
of forest ecosystem (CONECOFOR), J. Limnol. 2002;61:69-76.

20. Bytnerowicz A, Manning WJ, Grosjean D, et al. Detecting ozone and demonstrating its phytotoxicity in forested areas of Poland: A pilot study. Environ. Pollut. 1993;80:301-305.

21. Scheeren BA, Adema EH. Monitoring ambient ozone with a passive measurement technique method, field results and strategy. Water Air Soil Pollut. 1996;91:335-350.

22. Hauser TR, Bradley DW. Specific spectrophotometric determination of ozone in the atmosphere using 1,2-di-(4-pyridyl)ethylene. Anal. Chem. 1996;38:1529-1532.

23. Sekine Y, Butsugan M, Usuki H, Kitahara T. Evaluation of the diffusion sampling device for the determination of formaldehyde in indoor air. J. Environ. Chem. 2001;11:511-516.

24. Sekine Y, Hirota C, Butsugan M. Evaluation of solvent extraction type diffusion sampler for determination of VOCs in ambient air. J. Environ. Chem. 2002;12:847-854.

25. Sekine Y, Matsuo, A, Butsugan M. Evaluation of thermal desorption type diffusion sampler for determination of VOCs in ambient air. J. Environ. Chem. 2004;14:343-350.

26. Zeng M, Fang Z. Preparation of sub-micrometer porous membrane from chitosan/polyethylene glycol semi-IPN. J. Membrane Sci. 2004;245:95-102.

27. Wang J. W, Kuo YM. Preparation of Fructose-Mediated (Polyethylene glycol/Chitosan) Membrane and Adsorption of Heavy Metal Ions. J. Appl. Polym. Sci. 2007;105:1480-1489.

28. Gradko. United Kingdom. 2017. Technical Data Sheet: TDS 6: DIF 300 RTU-Ozone, Gradko Environmental Ltd,. St Martins House, 77 Wales Street, Winchester, SO23 0RH. United Kingdom.

29. Ogawa \& Co. USA, Inc. 2001. Sampling Protocol for Ozone Measurement Using The Ozone Passive Sampler Badge, Ogawa \& Co., USA, Inc.

30. Passam Switzerland.2013 Sampling Protocol Using The Passan Sampler. Passam \& Co., Switzerland. 2013.

31. Cecinato A, Palo VD, Possanzini M. Ozone Measurement with silica cartridges and HRGC-MS analysis. Fresenius J. Anal. Chem. 2001;369:652-656.

32. Linko YY, Pohjola L, Linko P. Entrapped glucose isomerase for high fructose syrup production. Proc. Biochem. 1977;12:14-16.

33. Sakimae A, Onishi H. Preparation of immobilized enzymes of micro-organisms. United States Patent 1981:4:276-381.

34. Kim JY, Ahn JH, Song SB, et al. Enhancement of the strength and stability of ultarviolet-irradiated acellular dermal matrix by adding glucose. Key Eng. Mater. 2007;342:337-340.

35. Kiuchi H, Kai W, Inoue Y. Preparation and characterization of poly(ethylene glycol) crosslinked chitosan films. J. Appl. Polym. Sci. 2008;107:3823-3830.

36. Sudha PN, Angelin VP, Sangeetha K, et al. Fabrication of cellulose acetate-chitosan-polyethylene glycol ultrafiltration membrane for chromium removal. Der Pharmacia Lettre 2014;6: 37-46.

37. Iraneta PC, Collamati RA, Costello DN, et al. A Validation Study of a New Active Sampler for the Analysis of Formaldehyde in Workplace and Indoor Air, Waters Corp., Milford, MA. Unpublished report for evaluation of method with Waters Sep-Pak XPoSure Aldehyde samplers. 1995.

38. Oxtoby D, Gillis, HP, Campion A, Principles of Modern Chemistry, 6th Edition. California: Thomson Brooks/Cole. 2008.

39. Campos VP, Cruz LPS, Godoi RHM, Godoi AFL, Tavares TM. Development and validation of passive samplers for atmospheric monitoring of $\mathrm{SO}_{2}, \mathrm{NO}_{2}, \mathrm{O}_{3}$ and $\mathrm{H}_{2} \mathrm{~S}$ in tropical areas. Microchem. J. 2010;96:132-138.

40. Yamamoto N, Hikono M, Koyama H, Kumagai K, Fujii M, Yanagisawa Y. A passive sampler for airborne coarse particles. J. Aerosol Sci. 2006;37:1442-1454.

41. Yay OD, Özden Ö, Altuğ H, et al. İskenderun-Payas bölgesinde pasif örnekleme ile hava kalitesinin ön değerlendirmesi. Air Pollution and Control Symposium; 22-25 October 2008; Hatay-Turkey. p.866-874.

42. Kara G, Bloemen H, Öztürk E, et al. Determination of Air Quality of Konya By Use of Passive Sampling Method. 5 th Air Pollution and Control Symposium; 18-20 September 2014; Eskişehir-Turkey. p. 557-570.

43. Tang YS, Cape JN, Sutton MA. Proceedings of the International Symposium on Passive Sampling of Gaseous Air Pollutants in Ecological Effects. International symposium on passive scientific world; 2001; p.513-529.

44. Evci M. Determination of ozone,nitrogen,dioxide and sulfur dioxide pollution around Aliağa by passive sampling Master of Science Thesis. İzmir: Dokuz Eylül University; 2009. 